\title{
REVIEW
}

\section{The role of the circadian clock in rheumatoid arthritis}

Julie E Gibbs* and David W Ray

\begin{abstract}
Rheumatoid arthritis exhibits diurnal variation in symptoms, with patients suffering with increased painful joint stiffness in the early morning. This correlates with an early morning rise in circulating levels of pro-inflammatory cytokines, such as interleukin-6. This temporal variation in disease pathology is directed by the circadian clock, both at a systemic level, through signalling pathways derived in the central clock, and at a local level by autonomous clocks found within inflammatory organs and cells. Indeed, many cellular components of the immune system, which are involved in the pathogenesis of rheumatoid arthritis, possess independent clocks that facilitate temporal gating of their functions. Furthermore, the circadian clock regulates the expression and activity of several genes and proteins that have demonstrated roles in progression of this autoimmune disease. These include a number of nuclear receptors and also fat-derived adipokines. Employing the knowledge we have about how the inflammatory response is regulated by the clock will facilitate the development of chronotherapy regimens to improve the efficacy of current treatment strategies. Furthermore, a full understanding of the mechanisms by which the clock couples to the immune system may provide novel therapeutic targets for the treatment of this debilitating disease.
\end{abstract}

\section{Introduction}

Symptoms of rheumatoid arthritis (RA) frequently show diurnal variation, with exacerbations in the morning (Figure 1) [1]. This variation in disease expression is accompanied by daily oscillations in circulating concentrations of disease-mediating cytokines [2]. In particular,

*Correspondence: Julie.gibbs@manchester.ac.uk

Institute of Human Development, School of Medicine, University of Manchester, AV Hill Building, Oxford Road, Manchester M13 9PT, UK
IL-6 shows robust oscillations, and fluctuations in serum IL-6 levels correlate with changes in disease symptoms [3]. This review summarises the evidence for a primary role for the circadian clock in the observed diurnal variations in disease activity, and its role in further aspects of RA disease manifestation. We consider how this information can be utilised, not only to modify existing treatment regimens, but to develop new therapeutic strategies to treat RA.

\section{The circadian clock}

The circadian clock drives daily rhythms in physiology necessary to synchronise the function of an organism with the 24-hour environment. Physiological functions under circadian control include the sleep-wake cycle, body temperature, heart rate, blood pressure, hormone regulation and immunity. These daily oscillations are orchestrated by a central pacemaker, which is found within the brain, in a hypothalamic region located above the optic chiasm called the suprachiasmatic nucleus $(\mathrm{SCN})$. The $\mathrm{SCN}$ receives light input from the eyes via the retinohypothalamic tract. The central pacemaker synchronises additional peripheral oscillators found locally within organs, tissues and cells (reviewed in [4]). These secondary clocks are synchronised by the central clock, but are self-sustaining and can be entrained by external cues such as temperature and feeding schedules.

The molecular machinery required to enable a cell to oscillate comprises a transcription/translation feedback loop (Figure 2). Central to this loop are the genes clock and bmal, whose encoded proteins dimerise (CLOCK/ BMAL) and bind to E-box elements on the promoters of the clock genes period (per), cryptochrome (cry), rev-erb and ror to activate their transcription. Translated PER and CRY form a dimeric complex (PER/CRY), enter the nucleus and inhibit CLOCK/BMAL transactivation. Subsequent degradation of PER/CRY allows CLOCK/ BMAL to start a new cycle of transcriptional activation. A second feedback loop is formed by the action of ROR and REV-ERB proteins on bmal transcription; these nuclear receptors activate (ROR) and repress (REV-ERB) transcription through their competitive action on response elements (ROREs) on the bmal promoter. 


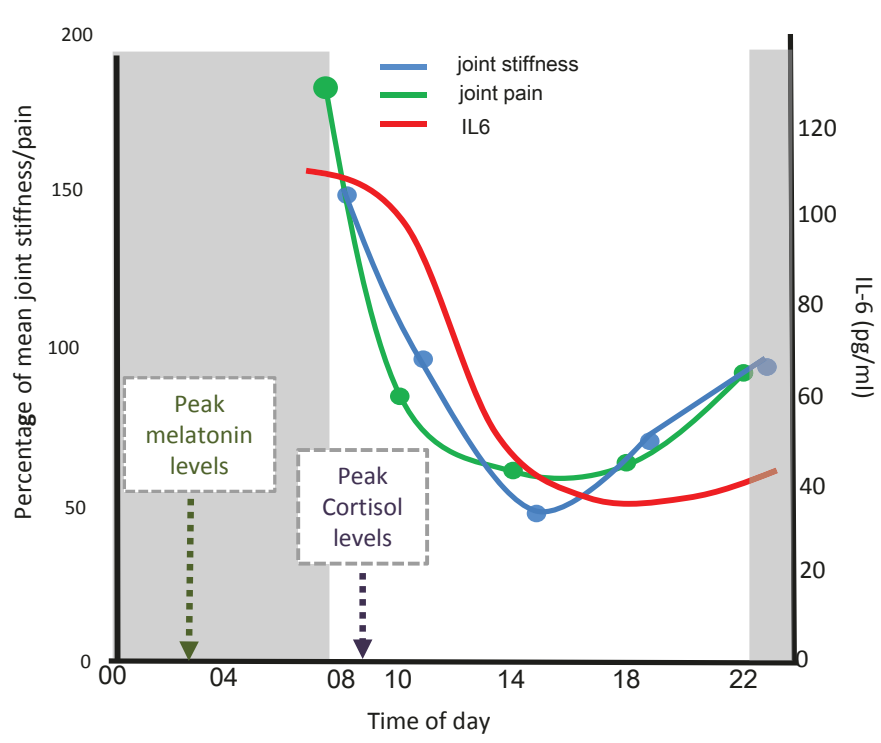

Figure 1. Rheumatoid arthritis shows diurnal variation in disease symptoms and markers. Joint stiffness and pain are more pronounced in the early morning [1], and this correlates with the early morning rise in plasma IL-6 levels [3]. The circadian hormone melatonin (which is considered to exacerbate the inflammatory response) is released only during the night, and circulating levels peak in the mid-night. The anti-inflammatory glucocorticoid - cortisol - is also under circadian control, peaking in the early morning.

Initially thought of as an auxillary stabilising loop, it is now considered that this circuit is required for circadian oscillation [5]. In addition to these core clock genes, numerous other 'clock-controlled genes' show circadian patterns of expression as a result of action on $\mathrm{E}$ boxes, $\mathrm{D}$ box enhancers, and RORE sites.

\section{Circadian regulation of the immune system}

The biological clock regulates many aspects of the immune system. As a consequence, immune responses often demonstrate measurable circadian variation. Several lines of evidence highlight the contribution of the circadian clock to the function of the immune system. Firstly, multiple immune cells possess the clockwork machinery and show daily variation in their function [6-8]. Secondly, disruption of the circadian clock has a detrimental effect on the function of the immune system. Finally, deletion of core clock genes can impact on immune responses. These established interactions between the clock and the immune system all have implications for RA.

\section{Oscillating immune cells; a source for rhythms in IL-6 levels}

Studies have revealed that the individual cellular components of the immune system that initiate and perpetuate inflammatory pathways are tightly regulated by the circadian clock. These include mast cells, natural killer cells, eosinophils, basophils, T lymphocytes and macrophages. As yet, the dominant cell type driving circadian disease expression in RA remains undetermined. One candidate that may underlie the rhythmic IL-6 secretion is the CD4+ T lymphocyte, which is considered a key mediator of RA with an established role in disease initiation and perpetuation. It has been shown that CD4+ $\mathrm{T}$ lymphocytes possess a circadian oscillator that drives rhythmic responses to activating stimuli, as manifest by altered cell proliferation and cytokine secretion [7,9]. In addition, macrophages possess an intrinsic clock, and over $8 \%$ of the macrophage transcriptome is under circadian control [6]. Although macrophages are not thought to be involved in the initiation of RA, their proinflammatory and tissue destructive actions contribute to disease expression and these phagocytes mediate joint inflammation and tissue destruction in erosive disease. A recent study demonstrated rhythmic IL-6 responses to stimulation by both human and mouse macrophages, and established the importance of the clock gene (and nuclear receptor) rev-erb $\alpha$ in generating these rhythms [10]. Finally, fibroblast like synoviocytes, located within the intimal lining of the synovium, also have a circadian oscillator [11]. These cells are a major source of proinflammatory cytokines in RA, although in active disease they may no longer oscillate. To summarise, a number of candidate cells may orchestrate the circadian oscillation in IL-6 secretion. However, the mechanism by which the clock exerts this control is not yet fully established. The production of IL- 6 by immune cells may fall under central clock control as a result of circulating mediators (such as glucocorticoids), or alternatively, local clocks 


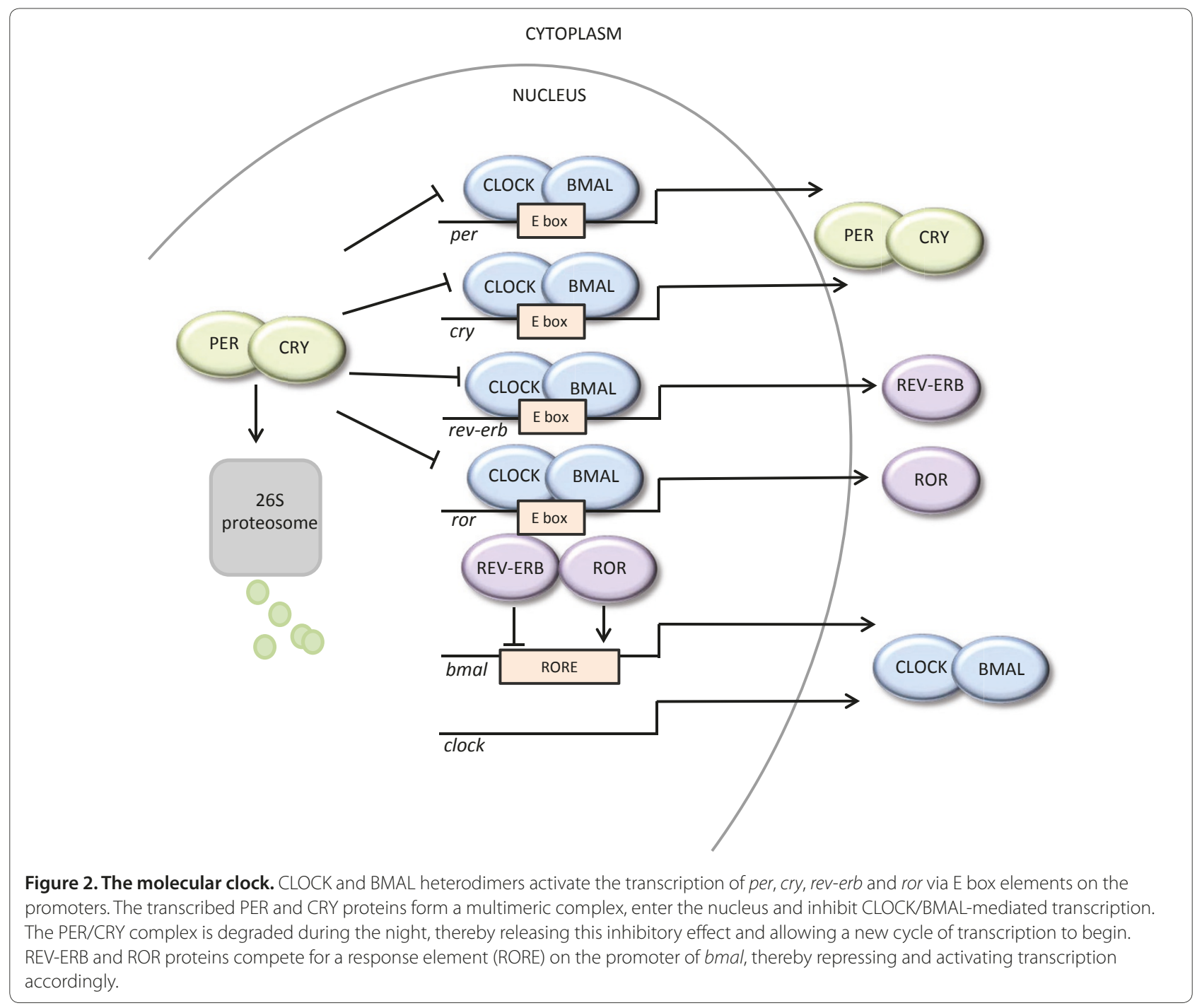

may directly drive IL-6 oscillations. Of course, both possibilities may co-exist.

\section{Disruption of the circadian clock and rheumatoid arthritis}

Recent studies have identified an intriguing bi-directional interaction between inflammation and the circadian clock. Disruption of the clock has a significant effect on the performance of the immune system, and there is a suggestion that this might impact negatively on the pathogenesis of RA. In converse, inflammation can directly alter cellular expression of core clock genes [12]. Disruption of the clock is exemplified by jet-lag, a consequence of de-synchrony between the internal clock and the environment, resulting in the need to re-set the phase of the clock. Depending on the number of time zones crossed and direction of travel, it can take a number of days to re-synchronise the body clock.
Shift-workers experience the same phenomenon. These constant shifts in the daily schedule are detrimental to health and have been linked with an increased incidence of a number of chronic diseases such as cancer, cardiovascular disease, metabolic syndromes, diabetes and irritable bowel syndrome [13]. Circadian disruption can be modelled by inducing 'chronic jet-lag' in animals through exposure to regular shifts in the lighting schedule. This type of environmental disturbance has negative effects on the function of immune cells, including macrophages and natural killer cells, and has detrimental effects on the survival of mice after immune challenge [14,15]. Interestingly, a study in 2010 provided a significant link between shift work and an increased risk of RA (in women) [16]. This is the first observation of its kind, supporting the concept that the body clock not only impacts on the symptoms of this disease, but is also involved in the pathogenesis. 


\section{Core clock genes - links with rheumatoid arthritis}

A direct link has been made between core components of the molecular clock and inflammatory pathways known to be relevant to RA. Mice lacking two core clock genes, cry 1 and cry2, show disruptions in their circadian clock. Where wild-type mice are able to maintain strong circadian behaviour in the absence of light cues, cry $1^{-1-}$ $c r y 2^{-/-}$mice are behaviourally arrhythmic under constant darkness. These double knockout mice have a more aggressive inflammatory arthritis in response to collagen induction (collagen-induced arthritis) [17]. This is attributed to the function of CRY as a transcriptional inhibitor of the $\operatorname{tnf} \alpha$ gene. It is now established that CRY acts on a broad range of pro-inflammatory target genes, which it modulates through the $\mathrm{NF}_{\kappa} B$ pathway [18]. Whilst this is the only established direct regulatory pathway linking the core clock and the pathogenesis of RA, several clock outputs (including hormones and clock-controlled genes) have been attributed roles, and these are expanded on below.

\section{Circadian control of the endocrine system and links with RA}

The endocrine system mediates the dissemination of timing signals from the SCN throughout the body. Two hormones in particular act as circadian agents - melatonin and glucocorticoids. Both are important in inflammation and regulation of the immune response, and may contribute to the pathogenesis of RA.

\section{Melatonin}

Melatonin is primarily secreted from the pineal gland (other sources include the retina, Harderian glands, intestine, skin, leukocytes and bone marrow). The SCN regulates melatonin synthesis through tonic inhibition of noradrenergic stimulation of the pineal gland. This hormone is only synthesized during the night (as synthesis is inhibited by daylight; Figure 1). Melatonin affects several aspects of the immune response, and is known to modulate pro-inflammatory cytokines, inhibit proliferation of fibroblast-like synoviocytes and regulate leukocyte function $[19,20]$. Interestingly, RA patients have altered levels of circulating melatonin [21]. Sulli and colleagues [21] report higher baseline levels of serum melatonin in RA patients (at the start and end of the dark phase) and an altered temporal profile with a more rapid increase at the start of the night and an earlier peak. These observations suggest that the effects of melatonin may be more pro-inflammatory than anti-inflammatory. In support, in vivo studies clearly indicate that melatonin has adverse effects on the development and severity of inflammatory arthritis. Administration of melatonin in a collagen-induced arthritis model resulted in enhanced disease incidence and severity [22]. This is concordant with studies showing that removal of the pineal gland, the main source of melatonin, has a beneficial effect on disease progression in the collagen-induced arthritis model [23]. It is important to consider that melatonin is widely available and often utilised by shift-workers and long-haul travellers, where it is thought to result in faster adaptation to a new time zone. Given that a clinical study of the use of melatonin in RA resulted in poor outcomes, with an increase in some markers of inflammation $[24,25]$, this current widespread use of melatonin may need to be addressed.

\section{Glucocorticoids}

Glucocorticoids are endogenous anti-inflammatory agents (cortisol in humans and corticosterone in rodents). Circulating levels fluctuate throughout the day in a circadian manner, peaking just before waking in mammals (Figure 1). The diurnal variation in circulating glucocorticoid concentrations is driven by the circadian clock through direct neural connections between the central clock in the SCN, and the paraventricular nucleus in the hypothalamus, the site of central control for the hypothalamic pituitary adrenal axis. Glucocorticoids act via the ubiquitously expressed glucocorticoid receptor (GR), a ligand-activated transcription factor, belonging to the nuclear receptor superfamily (see below). The activated, hormone bound GR translocates from the cytoplasm to the nucleus, and binds to target gene regulatory regions. Binding to positive glucocorticoid response elements as a homodimer results in transcriptional activation; and binding to negative glucocorticoid response elements results in transcriptional inhibition [26]. Additionally, ligand-bound GR can function as a transrepressor by binding (either directly or indirectly) to other transcription factors (such as activator protein-1 and $\mathrm{NF}_{\mathrm{K}} \mathrm{B}$ ) in a so-called tethering mechanism, to inhibit their trans-activating function and prevent their association with DNA [27-29]. Glucocorticoids can also exert rapid effects by coupling the GR to intracellular signalling cascades, including mitogen-activated protein and phosphoinositide-3 kinases [30]. This mechanism of action is less well-characterised, but offers potential cross-talk between growth factors and cytokine signalling, relevant to inflammatory arthritis, and glucocorticoid action.

In RA patients, the natural morning peak in cortisol levels occurs approximately 40 minutes after the morning rise in IL-6 levels [2]. It is a striking paradox that the stress-responsive hypothalamic pituitary adrenal axis is not constitutively activated in RA patients, and in fact, the dynamic responses to activation have been shown to be blunted, for reasons that remain obscure, but with obvious clinical implications [2]. Recent insights suggest that merely tracking circulating cortisol levels is inadequate as a means to assess glucocorticoid action. Indeed, 
in certain cell-types, expression of the GR shows daily rhythms; furthermore, the function of the receptor is under clock control, thereby suggesting alternative mechanisms by which the clock regulates glucocorticoid sensitivity.

\section{Nuclear receptors}

Nuclear receptors are ligand-dependent transcription factors, which modulate gene expression through direct binding to DNA response elements. Over half of the nuclear receptor family exhibit rhythmic expression in a tissue-specific manner [31], and many can feedback directly onto the clock itself. Nuclear receptors are recognised as key intermediaries between the molecular clock and a wide array of physiological processes, including immunity [32]. In the context of RA, three nuclear receptors are of particular interest: GR, retinoid-related orphan receptors (RORs) and peroxisome proliferator activated receptors (PPARs).

\section{Glucocorticoid receptor}

There are three protein isoforms of the GR ( $\alpha, \beta$ and $\gamma)$, of which GR $\alpha$ is the dominant form, mediating most of the actions of glucocorticoids. Evidence suggests that receptor levels show circadian variation in some tissues, but not others [31]. In addition, the cellular clock can drive post-translational modification of the GR protein, so affecting its function. This includes GR interaction with $\mathrm{NF}_{\mathrm{K}} \mathrm{B}$, which consequently affects the anti-inflammatory capacity of glucocorticoids. CLOCK and BMAL proteins can acetylate a cluster of lysine residues in the hinge region of the GR, which selectively attenuates the ability of the GR to bind to glucocorticoid response elements. The naturally occurring oscillations in CLOCK/BMAL levels consequently translate into circadian fluctuations in the acetylation of the GR; for example, in human peripheral blood mononuclear cells, acetylated GR is almost three-fold higher in the day [33]. An additional insight is provided by the recent discovery that GR and the core clock protein CRY form a dimer, which is critical to normal GR function. As CRY is only present for part of the circadian cycle this imposes indirect clock control upon the GR, with the suggestion that only specific aspects of GR function (including gluconeogenesis and hypothalamo-pituitary axis tone) show a circadian component [34]. This opens up a potential therapeutic opportunity whereby through altering the timing of delivery (chronotherapy) it may be possible to maximise the anti-inflammatory effects of glucocorticoids whilst alleviating the adverse metabolic effects.

\section{Retinoid-related orphan receptors}

RORs are a family of nuclear receptors with three members, ROR $\alpha, \operatorname{ROR} \beta$ and ROR $\gamma$ (of which there are two isoforms $\gamma$ and $\gamma \mathrm{t}$ ). Transcription of ror genes is rhythmic, although to varying degrees, and the ROR proteins have a well established role in the molecular clock via transcriptional control of bmal (mice deficient in either ROR $\alpha$ or ROR $\beta$ show aberrant circadian behaviour). The circadian rhythmic ROR $\alpha$ has a role in promoting the differentiation of $\mathrm{T}$ cells into $\mathrm{T}_{\mathrm{H}} 17$ cells. These are a subset of $\mathrm{T}$ helper cells (distinct from $\mathrm{T}_{\mathrm{H}} 1$, $\mathrm{T}_{\mathrm{H}} 2$ and regulatory $\mathrm{T}$ cells) characterised by their expression of the pro-inflammatory cytokines IL-17 and IL-17F, which represent a substantial population of infiltrating CD4+ T cells in inflamed synovial tissue [35]. In addition, ROR $\alpha$ has a role in regulating inflammation. Staggerer $(s g)$ mice, which carry a microdeletion in the rora gene preventing translation of the ligand binding homology domain, have immune system deficiencies. Macrophages isolated from $s g$ mice are hyper-responsive to lipopolysaccharide, producing elevated levels of cytokines (IL-1 $\beta$, TNF $\alpha$ and IL-1 $\alpha$ ) [36]. Further studies have identified direct interactions between ROR $\alpha$ and inflammatory genes. ROR $\alpha 1$ can activate IкB $\alpha$ (the main inhibitory protein in the NFKB pathway) via a response element on the promoter, thereby suppressing inflammatory responses [37]. Conversely, ROR $\alpha$ can up-regulate the inflammatory response through binding to a response element on the promoter of the il 6 gene to enhance IL- 6 production [38]. Of note, ROR $\gamma t$ also plays a key role in the differentiation of $\mathrm{T}$ cells into $\mathrm{T}_{\mathrm{H}} 17$ cells [39]; however, ROR $\gamma t$ expression is clock independent.

\section{Peroxisome proliferator activated receptors}

PPARs are a further class of nuclear receptors closely interlinked with the circadian clock. They are ligandactivated transcription regulators, which act by forming heterodimers with retinoic acid receptors (RXRs) and binding to response elements on target genes. All three PPARs $(\alpha, \beta / \delta$ and $\gamma)$ show tissue-specific patterns of circadian expression. Clock regulation of both the expression and function of PPARs is multifaceted. PPAR $\alpha$ transcription is directly regulated by CLOCK/BMAL via an Ebox element in the promoter. In comparison, the activity of PPAR $\gamma$ is regulated through the activity of circadian proteins, which include the transcriptional enhancer nocturin, the co-activator protein PGC-1 $\alpha$, and the core clock protein PER2 [40-42]. Endogenous ligands for PPARs include free fatty acids and eicosanoids and so in response to a high fat diet or fasting (when lipolysis in adipose tissue is active) these receptors become activated. The PPARs play a key role in lipid metabolism, energy partition, and also in regulating macrophage activity. Importantly, PPAR $\gamma$ and $\delta$ facilitate 'alternative' activation of macrophages - a cellular state that plays a key role in the resolution of inflammation [43]. In addition to modulating macrophage function, 
PPARs are regulators of T-cell function. Both PPAR $\alpha$ and $\gamma$ are expressed in T cells, $\alpha$ is down-regulated following T-cell activation, whilst $\gamma$ is up-regulated [44]. PPAR $\gamma$ is known to mediate the proliferative response of $\mathrm{T}$ cells, inhibits their differentiation into $\mathrm{T}_{\mathrm{H}} 17$ cells, and induces T-cell apoptosis [45-47].

\section{Adipokines}

The circadian clock is fundamental in the regulation of metabolic processes; controlling expression of genes involved in metabolic pathways but also responding to metabolic cues [32]. Circadian disruption has detrimental effects on metabolism, and is an exacerbating factor in the incidence of metabolic syndrome, which itself is associated with the risk of developing RA [48]. It is proposed that the link between metabolic syndrome and RA is due to the inflammatory milieu associated with metabolic syndrome, much of which is provided by the increased quantities of adipose tissue, which secretes elevated levels of cytokines (TNF $\alpha$ and IL-6) and adipokines. Adipokines are signalling molecules produced primarily by adipose tissue and include adiponectin, leptin, resistin and visfatin. White adipose tissue and its constituent adipocytes are both circadian rhythmic, and many adipokines exhibit 24-hour variation in plasma concentrations [49]. Recent studies have identified clear associations between adipokines and the pathophysiology of rheumatic diseases. For example, visfatin (also known as nicotinamide phosphoribosyltransferase (NAMPT) or pre-B cell colony-enhancing factor (PBEF)) is released by visceral fat, macrophages, liver, skeletal muscle and leukocytes in a rhythmic manner to produce diurnal rhythms in circulating levels [50]. Elevated levels of visfatin are associated with RA; furthermore, levels detected in serum and synovial fluid correlate with clinical disease severity [51]. Visfatin is pro-inflammatory, and although the underlying mechanisms are not fully understood, it stimulates synovial fibroblasts and monocytes to release pro-inflammatory cytokines and matrix metalloproteinases. The well-established and complex relationship between the circadian clock and metabolic processes provides another link between the clock and the pathogenesis of RA.

\section{Targeting clock output genes as therapeutics}

Synthetic glucocorticoids, such as dexamethasone and prednisone, have long been a cornerstone in the clinical treatment of RA. Yet, prolonged usage is associated with a number of adverse effects, including immune suppression, metabolic imbalance and diabetes. Although the recent development of biologics (which specifically target components of the immune system that play pivotal roles in driving inflammation) has made great advances in the treatment of RA, these unfortunately are known to increase the risk of infection (that is, tuberculosis and hepatitis B). Consequently, there remains a need to develop new therapies for the treatment of this inflammatory disorder.

Given that RORs and PPARs have significant input into key events that contribute to the pathogenesis of RA, both present as potential therapeutic targets in this, and other, inflammatory diseases. Many synthetic PPAR ligands are already in clinical use. The thiazolidinediones are a group of synthetic PPAR $\gamma$ ligands that have anti-hyperglycemic actions and are used in the management of type 2 diabetes. They include rosiglitazone, troglitazone and pioglitazone. Synthetic PPARY ligands, and the proposed endogenous ligand 15-deoxy-delta $(12,14)$-prostoglandin $\mathrm{J}_{2}$ are antiinflammatory, and improve outcome in animal models of inflammatory arthritis [52-54]. Recently, a clinical trial has suggested that the concomitant use of pioglitazone and methotrexate may have synergistic effects in RA [55]. However, although these compounds have potent antiinflammatory properties, off-target effects, possibly through activation of the glucocorticoid receptor [56], can result in osteoporosis or cardiac failure, which is likely to limit their application. Similarly, there is growing evidence that PPAR $\alpha$ agonists may be useful in the treatment of RA. Synthetic PPAR $\alpha$ ligands include fibrates (fenofibrate, gemfibrozil and clofibrate), hypolipidemic compounds already utilised in the treatment of metabolic disorders. Promisingly, fenofibrate has been shown to be effective at reducing inflammation in experimental arthritis models [57].

\section{Novel therapeutic targets}

A full understanding of the network through which the circadian clock regulates inflammatory pathways is likely to provide novel therapeutic targets for treating RA and other inflammatory disorders and autoimmune conditions. Given its role in T-cell function, one such target is ROR. A novel synthetic ligand for ROR ( $\alpha$ and $\gamma$ ) has recently been synthesised (SR1001) that inhibits $\mathrm{T}_{\mathrm{H}} 17$ cell differentiation and reduces the severity of murine experimental autoimmune encephalomyelitis, a $\mathrm{T}_{\mathrm{H}} 17$ cellmediated autoimmune disease [58]. In addition, another key area for therapeutic targeting is the molecular clock. Given the role of CRY in regulating inflammatory pathways, the recently identified CRY activator KLO01 may prove to have anti-inflammatory properties beneficial in the treatment of RA [59]. Finally, our relatively recent understanding of the role of adipokines in rheumatic disease suggests that these circadian-regulated molecules could be explored as a new avenue of treatment.

\section{Chronotherapy for the treatment of rheumatic arthritis}

Chronotherapy refers to the application of information about circadian rhythms in therapeutics. An understanding 


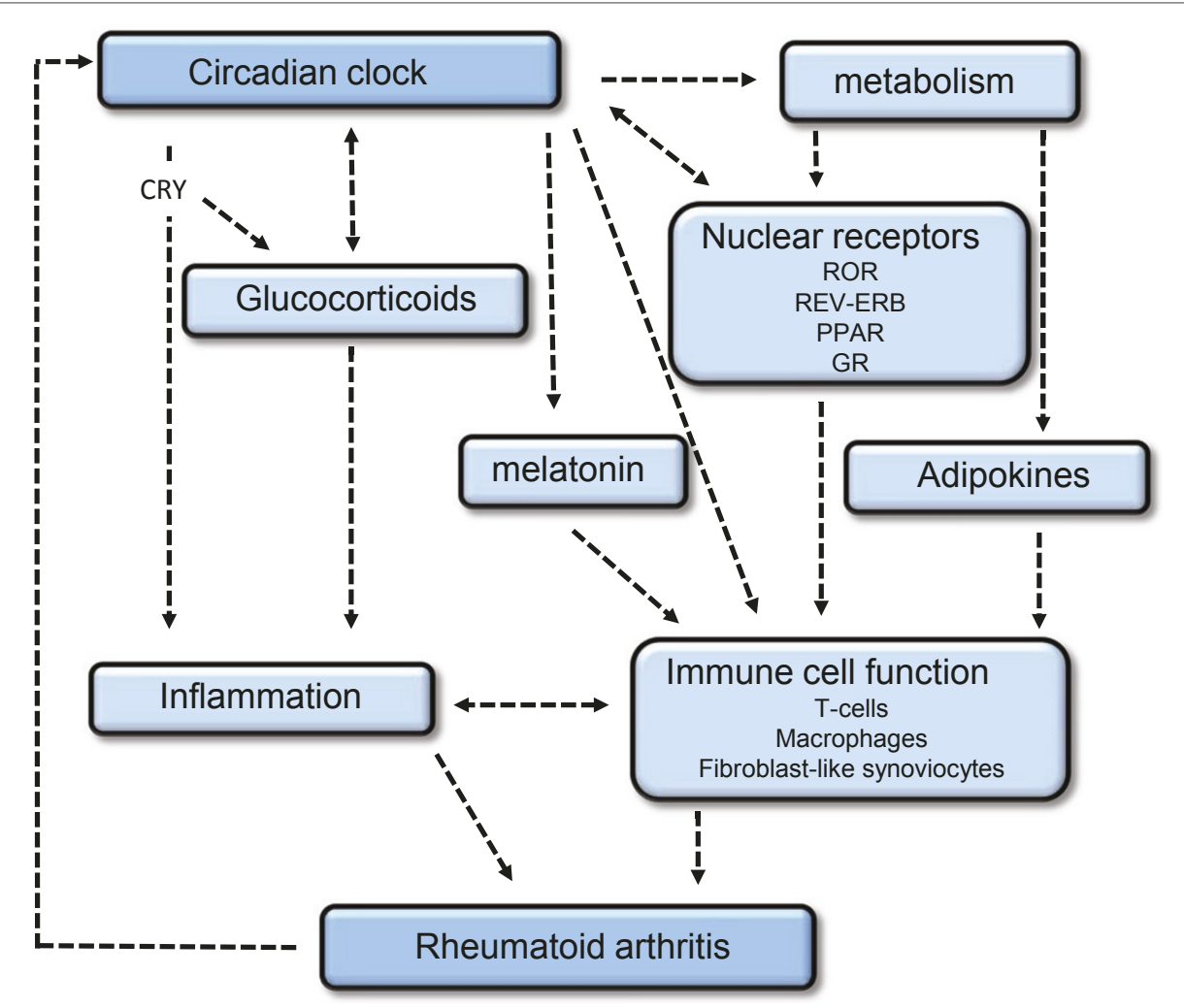

Figure 3. Interactions between the circadian clock and the immune system that contribute to disease pathogenesis in rheumatoid arthritis. GR, glucocorticoid receptor; PPAR, peroxisome proliferator activated receptor; ROR, retinoic acid related orphan receptor.

of how the clock influences expression of the drug target or elements of the drug's metabolic pathway can be utilised to optimise dosing times to make treatment more effective; this might maximise effectiveness and minimise side effects. Given the strong circadian component to RA, there is obvious potential for the use of chronotherapy in the treatment of this disease. As proof of principle, a study in 1997 demonstrated the advantages of administering prednisone overnight, just prior to the rise in IL-6 levels and joint stiffness [60]. This small study identified a significant improvement in joint stiffness when this glucocorticoid was administered at 2:00 am versus 7:30 am. In response to the impractical nature of dosing during the night-time, modified release prednisone (Lodotra) has been developed. The CAPRA-1 study compared the effectiveness of Lodotra with immediate release prednisone in patients with active RA receiving disease-modifying anti-rheumatic drugs [61,62]. The group receiving Lodotra demonstrated significant improvements in the duration of their morning joint stiffness after just 2 weeks. Lodotra significantly reduced morning IL-6 levels, which was not seen in the immediate-release prednisone group. These beneficial effects over immediate-release prednisone were sustained over a 12 month period [63]. Furthermore, in a placebo-controlled study (CAPRA-2) the addition of lowdose (5 mg) Lodotra to existing treatment regimes proved to be beneficial [62]. These trials highlight the positive effects of chronotherapy on relieving morning joint pain and stiffness, and are the first of their kind to show that modification of pharmacokinetics and the application of timed-dosing can boost the effectiveness of established RA therapies. It is expected that application of chronotherapy to alternative types of RA therapies may prove similarly beneficial.

\section{Conclusion}

RA has long been known to have a circadian component, not just in its symptoms, but in disease biomarkers. It is only in recent years, however, that the importance of the circadian clock in regulating the immune response has been recognised. This control is exerted both at a systemic level, through signalling pathways originating in the central clock, and at the local level by autonomous clocks in inflammatory cells and tissues (Figure 3). The biological clock directly regulates processes that contribute to the pathogenesis of RA, such as the production of inflammatory cytokines by immune cells. In addition, clock-regulated adipokines and nuclear receptors contribute to processes integral to disease progression, such as 
inflammation and T-cell activation. A greater understanding of how the clock couples to the immune system, and the involvement of clock outputs in disease pathogenesis, is likely to produce novel therapeutic targets for the treatment of not only RA but also other inflammatory disorders. Harnessing the knowledge we have about how the inflammatory response is regulated by the clock to develop chronotherapy regimens has already proved valuable, and there is much scope to develop this area to improve the efficacy and reduce adverse effects of both current and new treatment strategies.

\section{Abbreviations}

GR, glucocorticoid receptor; IL, interleukin; NF, nuclear factor; PPAR, peroxisome proliferator activated receptor; RA, rheumatoid arthritis; ROR, retinoic acid related orphan receptor; RORE, response element; SCN, suprachiasmatic nucleus; TNF, tumour necrosis factor.

\section{Competing interests}

The authors declare that they have no competing interests.

\section{Acknowledgments}

We wish to thank Professor Andrew Loudon, University of Manchester, for his appraisal of the manuscript.

Published: 21 February 2013

\section{References}

1. Ingpen ML: The quantitative measurement of joint changes in rheumatoid arthritis. Ann Phys Med 1968, 9:322-327.

2. Perry MG, Kirwan JR, Jessop DS, Hunt LP: Overnight variations in cortisol, interleukin 6, tumour necrosis factor alpha and other cytokines in people with rheumatoid arthritis. AnnRheumDis 2009, 68:63-68.

3. Arvidson NG, Gudbjornsson B, Elfman L, Ryden AC, Totterman $T H$, Hallgren R: Circadian rhythm of serum interleukin- 6 in rheumatoid arthritis. Ann Rheum Dis 1994, 53:521-524.

4. Albrecht U: Timing to perfection: the biology of central and peripheral circadian clocks. Neuron 2012, 74:246-260.

5. Relogio A, Westermark PO, Wallach T, Schellenberg K, Kramer A, Herzel H: Tuning the mammalian circadian clock: robust synergy of two loops. PLOS Comput Biol 2011, 7:e1002309.

6. Keller M, Mazuch J, Abraham U, Eom GD, Herzog ED, Volk HD, Kramer A, Maier $B$ : A circadian clock in macrophages controls inflammatory immune responses. Proc Natl Acad Sci USA 2009, 106:21407-21412.

7. Bollinger T, Leutz A, Leliavski A, Skrum L, Kovac J, Bonacina L, Benedict C, Lange T, Westermann J, Oster H, Solbach W: Circadian clocks in mouse and human CD4+T cells. PLoS One 2011, 6:e29801.

8. Wang X, Reece SP, Van Scott MR, Brown JM: A circadian clock in murine bone marrow-derived mast cells modulates IgE-dependent activation in vitro. Brain Behav Immun 2011, 25:127-134.

9. Fortier EE, Rooney J, Dardente H, Hardy MP, Labrecque N, Cermakian N: Circadian variation of the response of T cells to antigen. J Immuno/ 2011, 187:6291-6300

10. Gibbs JE, Blaikley J, Beesley S, Matthews L, Simpson KD, Boyce SH, Farrow SN, Else KJ, Singh D, Ray DW, Loudon AS: The nuclear receptor REV-ERBalpha mediates circadian regulation of innate immunity through selective regulation of inflammatory cytokines. Proc Natl Acad Sci U S A 2012, 109:582-587.

11. Haas S, Straub RH: Disruption of rhythms of molecular clocks in primary synovial fibroblasts of patients with osteoarthritis and rheumatoid arthritis, role of IL-1 beta/TNF. Arthritis Res Ther 2012, 14:R122.

12. Coogan AN, Wyse CA: Neuroimmunology of the circadian clock. Brain Res 2008, 1232:104-112.

13. Wang XS, Armstrong ME, Cairns BJ, Key TJ, Travis RC: Shift work and chronic disease: the epidemiological evidence. Occup Med (Lond) 2011, 61:78-89.

14. Castanon-Cervantes O, Wu M, Ehlen JC, Paul K, Gamble KL, Johnson RL, Besing RC, Menaker M, Gewirtz AT, Davidson AJ: Dysregulation of inflammatory responses by chronic circadian disruption. J Immunol 2010, 185:5796-5805.
15. Logan RW, Zhang C, Murugan S, O'Connell S, Levitt D, Rosenwasser AM, Sarkar DK: Chronic shift-lag alters the circadian clock of NK cells and promotes lung cancer growth in rats. J Immunol 2012, 188:2583-2591.

16. Puttonen S, Oksanen T, Vahtera J, Pentti J, Virtanen M, Salo P, Kivimaki M: Is shift work a risk factor for rheumatoid arthritis? The Finnish Public Sector study. Ann Rheum Dis 2010, 69:779-780.

17. Hashiramoto A, Yamane T, Tsumiyama K, Yoshida K, Komai K, Yamada H, Yamazaki F, Doi M, Okamura H, Shiozawa S: Mammalian clock gene Cryptochrome regulates arthritis via proinflammatory cytokine TNF-alpha. Jlmmunol 2010, 184:1560-1565.

18. Narasimamurthy R, Hatori M, Nayak SK, Liu F, Panda S, Verma IM: Circadian clock protein cryptochrome regulates the expression of proinflammatory cytokines. Proc Natl Acad Sci U S A 2012, 109:12662-12667.

19. Radogna F, Diederich M, Ghibelli L: Melatonin: a pleiotropic molecule regulating inflammation. Biochem Pharmacol 2010, 80:1844-1852.

20. Nah SS, Won HJ, Park HJ, Ha E, Chung JH, Cho HY, Baik HH: Melatonin inhibits human fibroblast-like synoviocyte proliferation via extracellular signalregulated protein kinase/P21(CIP1)/P27(KIP1) pathways. J Pineal Res 2009, 47:70-74.

21. Sulli A, Maestroni GJ, Villaggio B, Hertens E, Craviotto C, Pizzorni C, Briata M, Seriolo B, Cutolo M: Melatonin serum levels in rheumatoid arthritis. Ann NY Acad Sci 2002, 966:276-283

22. Hansson I, Holmdahl R, Mattsson R: The pineal hormone melatonin exaggerates development of collagen-induced arthritis in mice. J Neuroimmunol 1992, 39:23-30.

23. Hansson I, Holmdahl R, Mattsson R: Pinealectomy ameliorates collagen II-induced arthritis in mice. Clin Exp/mmunol 1993, 92:432-436.

24. Forrest CM, Mackay GM, Stoy N, Stone TW, Darlington LG: Inflammatory status and kynurenine metabolism in rheumatoid arthritis treated with melatonin. Br J Clin Pharmacol 2007, 64:517-526.

25. Cutolo M, Straub RH, Buttgereit F: Circadian rhythms of nocturnal hormones in rheumatoid arthritis: translation from bench to bedside. Ann Rheum Dis 2008, 67:905-908.

26. Surjit M, Ganti KP, Mukherji A, Ye T, Hua G, Metzger D, Li M, Chambon P: Widespread negative response elements mediate direct repression by agonist-liganded glucocorticoid receptor. Cell 2011, 145:224-241.

27. MCMaster A, Ray DW: Modelling the glucocorticoid receptor and producing therapeutic agents with anti-inflammatory effects but reduced side-effects. Exp Physiol 2007, 92:299-309.

28. Rhen T, Cidlowski JA: Antiinflammatory action of glucocorticoids--new mechanisms for old drugs. N Engl J Med 2005, 353:1711-1723.

29. Uhlenhaut NH, Barish GD, Yu RT, Downes M, Karunasiri M, Liddle C, Schwalie P, Hubner N, Evans RM: Insights into negative regulation by the glucocorticoid receptor from genome-wide profiling of inflammatory cistromes. Mol Cell 2013, 49:1-14.

30. Stahn C, Buttgereit F: Genomic and nongenomic effects of glucocorticoids. Nat Clin Pract Rheumatol 2008, 4:525-533.

31. Yang X, Downes M, Yu RT, Bookout AL, He W, Straume M, Mangelsdorf DJ, Evans RM: Nuclear receptor expression links the circadian clock to metabolism. Cell 2006, 126:801-810.

32. Bechtold DA, Gibbs JE, Loudon AS: Circadian dysfunction in disease. Trends Pharmacol Sci 2010, 31:191-198.

33. Charmandari E, Chrousos GP, Lambrou Gl, Pavlaki A, Koide H, Ng SS, Kino T: Peripheral CLOCK regulates target-tissue glucocorticoid receptor transcriptional activity in a circadian fashion in man. PLoS One 2011, 6:e25612.

34. Lamia KA, Papp SJ, Yu RT, Barish GD, Uhlenhaut NH, Jonker JW, Downes M, Evans RM: Cryptochromes mediate rhythmic repression of the glucocorticoid receptor. Nature 2011, 480:552-556.

35. Ivanov, II, McKenzie BS, Zhou L, Tadokoro CE, Lepelley A, Lafaille JJ, Cua DJ, Littman DR: The orphan nuclear receptor RORgammat directs the differentiation program of proinflammatory IL-17+T helper cells. Cell 2006, 126:1121-1133.

36. Kopmels B, Mariani J, Delhaye-Bouchaud N, Audibert F, Fradelizi D, Wollman EE: Evidence for a hyperexcitability state of staggerer mutant mice macrophages. J Neurochem 1992, 58:192-199.

37. Delerive P, Monte D, Dubois G, Trottein F, Fruchart-Najib J, Mariani J, Fruchart JC, Staels B: The orphan nuclear receptor ROR alpha is a negative regulator of the inflammatory response. EMBO Rep 2001, 2:42-48.

38. Journiac N, Jolly S, Jarvis C, Gautheron V, Rogard M, Trembleau A, Blondeau JP, Mariani J, Vernet-der GB: The nuclear receptor ROR(alpha) exerts a 
bi-directional regulation of IL- 6 in resting and reactive astrocytes. Proc Nat/ Acad SciU S A 2009, 106:21365-21370.

39. Eberl G, Littman DR: The role of the nuclear hormone receptor RORgammat in the development of lymph nodes and Peyer's patches. Immunol Rev 2003, 195:81-90

40. Kawai M, Green CB, Lecka-Czernik B, Douris N, Gilbert MR, Kojima S, Ackert-Bicknell C, Garg N, Horowitz MC, Adamo ML, Clemmons DR, Rosen CJ: A circadian-regulated gene, Nocturnin, promotes adipogenesis by stimulating PPAR-gamma nuclear translocation. Proc Natl Acad SciU S A 2010, 107:10508-10513.

41. Liu C, Li S, Liu T, Borijgin J, Lin JD: Transcriptional coactivator PGC-1alpha integrates the mammalian clock and energy metabolism. Nature 2007, 447:477-481.

42. Grimaldi B, Bellet MM, Katada S, Astarita G, Hirayama J, Amin RH, Granneman JG, Piomelli D, LeffT, Sassone-Corsi P: PER2 controls lipid metabolism by direct regulation of PPARgamma. Cell Metab 2010, 12:509-520.

43. Chawla A: Control of macrophage activation and function by PPARs. Circ Res 2010, 106:1559-1569.

44. Jones DC, Ding X, Daynes RA: Nuclear receptor peroxisome proliferatoractivated receptor alpha (PPARalpha) is expressed in resting murine lymphocytes. The PPARalpha in T and B lymphocytes is both transactivation and transrepression competent. J Biol Chem 2002, 277:6838-6845

45. Klotz L, Burgdorf S, Dani I, Saijo K, Flossdorf J, Hucke S, Alferink J, Nowak N, Beyer M, Mayer G, Langhans B, Klockgether T, Waisman A, Eberl G, Schultze J, Famulok M, Kolanus W, Glass C, Kurts C, Knolle PA: The nuclear receptor PPAR gamma selectively inhibits Th17 differentiation in a T cell-intrinsic fashion and suppresses CNS autoimmunity. J Exp Med 2009, 206:2079-2089.

46. Clark RB, Bishop-Bailey D, Estrada-Hernandez T, Hla T, Puddington L, Padula SJ: The nuclear receptor PPAR gamma and immunoregulation: PPAR gamma mediates inhibition of helper T cell responses. J Immuno/ 2000, 164:1364-1371

47. Harris SG, Phipps RP: Induction of apoptosis in mouse T cells upon peroxisome proliferator-activated receptor gamma (PPAR-gamma) binding. Adv Exp Med Biol 2002, 507:421-425.

48. Gremese E, Ferraccioli G: The metabolic syndrome: the crossroads between rheumatoid arthritis and cardiovascular risk. Autoimmun Rev 2011, 10:582-589.

49. Johnston JD: Adipose circadian rhythms: translating cellular and animal studies to human physiology. Mol Cell Endocrinol 2012, 349:45-50.

50. Benedict C, Shostak A, Lange T, Brooks SJ, Schioth HB, Schultes B, Born J, Oster $H$, Hallschmid M: Diurnal rhythm of circulating nicotinamide phosphoribosyltransferase (Nampt/visfatin/PBEF): impact of sleep loss and relation to glucose metabolism. J Clin Endocrinol Metab 2012 97:E218-222.

51. Gomez R, Conde J, Scotece M, Gomez-Reino JJ, Lago F, Gualillo O: What's new in our understanding of the role of adipokines in rheumatic diseases? Nat Rev Rheumatol 2011, 7:528-536.

52. Tomita T, Kakiuchi Y, Tsao PS: THR0921, a novel peroxisome proliferatoractivated receptor gamma agonist, reduces the severity of collageninduced arthritis. Arthritis Res Ther 2006, 8:R7.
53. Song JS, Kim CH, Heo JY, Cho YS: Rosiglitazone reduces a wide range of proinflammatory profiles in synovial fibroblast SW982 under spheroid culture. Immunol Lett 2010, 131:81-88.

54. Lin TH, Tang CH, Wu K, Fong YC, Yang RS, Fu WM: 15-deoxy-Delta(12,14) -prostaglandin-J2 and ciglitazone inhibit TNF-alpha-induced matrix metalloproteinase 13 production via the antagonism of NF-kappaB activation in human synovial fibroblasts. J Cell Physio/ 2011, 226:3242-3250

55. Shahin D, Toraby EE, Abdel-Malek H, Boshra V, Elsamanoudy AZ, Shaheen D: Effect of peroxisome proliferator-activated receptor gamma agonist (pioglitazone) and methotrexate on disease activity in rheumatoid arthritis (experimental and clinical study). Clin Med Insights Arthritis Musculoskelet Disord 2011, 4:1-10.

56. Matthews L, Berry A, Tersigni M, D'Acquisto F, lanaro A, Ray D: Thiazolidinediones are partial agonists for the glucocorticoid receptor. Endocrinology 2009, 150:75-86.

57. Okamoto H, Iwamoto T, Kotake S, Momohara S, Yamanaka H, Kamatani N: Inhibition of NF-kappaB signaling by fenofibrate, a peroxisome proliferator-activated receptor-alpha ligand, presents a therapeutic strategy for rheumatoid arthritis. Clin Exp Rheumatol 2005, 23:323-330.

58. Solt LA, Kumar N, Nuhant P, Wang Y, Lauer JL, Liu J, Istrate MA, Kamenecka TM, Roush WR, Vidović D, Schürer SC, Xu J, Wagoner G, Drew PD, Griffin PR, Burris TP: Suppression of TH17 differentiation and autoimmunity by a synthetic ROR ligand. Nature 2011, 472:491-494

59. Hirota T, Lee JW, St John PC, Sawa M, Iwaisako K, Noguchi T, Pongsawakul PY, Sonntag T, Welsh DK, Brenner DA, Doyle FJ 3rd, Schultz PG, Kay SA: Identification of small molecule activators of cryptochrome. Science 2012, 337:1094-1097.

60. Arvidson NG, Gudbjornsson B, Larsson A, Hallgren R: The timing of glucocorticoid administration in rheumatoid arthritis. Ann Rheum Dis 1997 56:27-31.

61. Buttgereit F, Doering G, Schaeffler A, Witte S, Sierakowski S, Gromnica-Ihle E, Jeka S, Krueger K, Szechinski J, Alten R: Efficacy of modified-release versus standard prednisone to reduce duration of morning stiffness of the joints in rheumatoid arthritis (CAPRA-1): a double-blind, randomised controlled trial. Lancet 2008, 371:205-214.

62. Buttgereit F, Mehta D, Kirwan J, Szechinski J, Boers M, Alten RE, Supronik J, Szombati I, Romer U, Witte S, Saag KG: Low-dose prednisone chronotherapy for rheumatoid arthritis: a randomised clinical trial (CAPRA-2). Ann Rheum Dis 2012, 72:204-210

63. Buttgereit F, Doering G, Schaeffler A, Witte S, Sierakowski S, Gromnica-Ihle E, Jeka S, Krueger K, Szechinski J, Alten R: Targeting pathophysiological rhythms: prednisone chronotherapy shows sustained efficacy in rheumatoid arthritis. Ann Rheum Dis 2010, 69:1275-1280.

doi:10.1186/ar4146

Cite this article as: Gibbs JE, Ray DW: The role of the circadian clock in

rheumatoid arthritis. Arthritis Research \& Therapy 2013, 15:205. 